\title{
School bullying and the mechanisms of moral disengagement
}

Robert Thornberg and Tomas J ungert

The self-archived postprint version of this journal article is available at Linköping University Institutional Repository (DiVA):

http:/ / urn.kb.se/ resolve?urn=urn:nbn:se:liu:diva-105637

N.B.: When citing this work, cite the original publication.

Thornberg, R., J ungert, T., (2014), School bullying and the mechanisms of moral disengagement, Aggressive Behavior, 40(2), 99-108. https:// doi.org/ 10.1002/ ab.21509

Original publication available at:

https:/ / doi.org/ 10.1002/ ab.21509

Copyright: Wiley (12 months)

http:/ / eu.wiley.com/WileyCDA/ 
School Bullying and the Mechanisms of Moral Disengagement

\section{Robert Thornberg \& Tomas Jungert}

\section{Linköping University}

The aim of the present study was to examine to what degree different mechanisms of moral disengagement were related to age, gender, bullying, and defending among school children. Three hundred and seventy-two Swedish children ranging in age from 10 to 14 years completed a questionnaire. Findings revealed that boys expressed significantly higher levels of moral justification, euphemistic labeling, diffusion of responsibility, distorting consequences, and victim attribution, as compared with girls. Whereas boys bullied others significantly more often than girls, age was unrelated to bullying. Moral justification and victim attribution were the only dimensions of moral disengagement that significantly related to bullying. Furthermore, younger children and girls were more likely to defend victims. Diffusion of responsibility and victim attribution were significantly and negatively related to defending, while the other dimensions of moral disengagement were unrelated to defending.

\section{Introduction}

Morality could be defined as conceptions of human welfare, justice and rights, and regulation of actions that affect others in these terms (Nucci, 2001; Turiel, 1983). Congruent with this definition, bullying is an example of immoral actions because of its repeated harmful intentions and consequences toward someone in a weaker position (Hymel, Schonert-Reichl, Bonanno, Vaillancourt, \& Rocke Henderson, 2010). Even during the early preschool years, children distinguish between morality and convention, justifying their judgments of moral issues in terms of the harm or unfairness that given actions cause (for a review, see Nucci, 2001). Most children consider bullying highly immoral (Menesini et al., 1997; Thornberg, 2010a); 
therefore, it might be seen as anomalous that bullying does take place among children, and that they seldom intervene as bystanders (Craig \& Pepler, 1998; Craig, Pepler, \& Atlas, 2000; Hawkins, Pepler, \&Craig, 2001; O’Connell, Pepler, \&Craig, 1999).

\section{Moral Disengagement}

According to social cognitive theory (Bandura, 1997, 1999, 2002, 2004), the exercise of moral agency has two facets. The inhibitive form is manifested in the power to refrain from acting inhumanely, such as by harassing or bullying others. The proactive form of morality is expressed in the power to act humanely, such as helping or defending a victim in a bullying situation. Nevertheless, people do not always regulate their actions in accordance with moral standards. "Self-regulatory mechanisms do not come into play unless they are activated, and there are many social and psychological maneuvers by which moral self-sanction can be disengaged from inhumane conduct” (Bandura, 1999, p. 194). Moral disengagement refers to such socio-cognitive maneuvers, which permit people to disengage from moral standards without any feelings of remorse, guilt or self-condemnation.

Specifically, Bandura proposed eight moral disengagement mechanisms clustered into four major domains. The first domain, cognitive restructuring, refers to the reconstrual of the conduct itself, so that it is not viewed as immoral as a result of moral justification (using worthy ends or moral purposes to sanctify pernicious means), euphemistic labeling (labeling the negative or harmful act in a way that makes the act sound less negative or more respectable) or, advantageous comparison (making a bad act seem less bad by comparing it to a worse or more negative act). Minimizing one's agentive role is the second major domain, and refers to detaching or obscuring oneself from personal responsibility for the harmful act through either displacement of responsibility (viewing one's actions as stemming from authorities), or diffusion of responsibility (diluting personal responsibility due to the presence or involvement of 
other people). The third set of moral disengagement mechanisms operates by disregarding or distorting the consequences, (minimizing, ignoring, or misconstruing the negative or harmful effects of actions). The fourth and final domain victim attribution, avoids moral stress by dehumanization (stripping the victim of human qualities and equal values) or blaming the victim (believing that the victim deserves his or her suffering).

As compared to their peers, children with higher moral disengagement display more aggression (Bandura, Barbaranelli, Caprara, \& Pastorelli, 1996; Bandura, Caprara, Barbaranelli, \& Pastorelli, 2001; Barchia \& Bussey, 2010; Paciello, Fida, Tramontano, Lupinetti, \& Caprara, 2008; Pelton, Gound, Forehand, \& Brody, 2004; Pornari \& Wood, 2010), including bullying and pro-bullying behavior (Almedia, Correia, \& Marinho, 2010; Gini, Pozzoli, \& Hauser, Gini et al., 20112011; Hymel, Rocke-Henderson, \&Bonanno, 2005; Menesini et al., 2003; Obermann, 2011b; Perren \& Gutzwiller-Helfenfinger, 2012; Perren et al., 2012; Thornberg \& Jungert, 2013a), as well as less empathy (Almedia et al., 2010; Barriga, SullivanCosetti, \& Gibbs, 2009; Hyde et al., 2010), fewer feelings of guilt regarding behavior transgressions (Bandura et al., 1996; Perren \& Gutzwiller-Helfenfinger, 2012), and less prosocial behavior (Bandura et al., 1996, 2001), including defending victims from bullying behavior (Almedia et al., 2010; Gini, 2006; Obermann, 2011a; Thornberg \& Jungert, 2013a). However, children's proneness to moral disengagement has been found to be unrelated to their own degree of bullying victimization (Gini, 2006; Obermann, 2011b), which makes sense because being a victim involves neither aggressive nor prosocial behavior toward others. Furthermore, previous research has shown a relation between moral disengagement and gender: Boys tend to become morally disengaged more than girls (Almedia et al., 2010; Bandura et al., 1996, 2001; Barchia \& Bussey, 2010; Obermann, 2011b; Perren \& GutzwillerHelfenfinger, 2012; Thornberg \& Jungert, 2013a). 
However, even though moral disengagement is a multidimensional construct, research has traditionally measured moral disengagement as a unidimensional construct. Factor analyses of previous moral disengagement scales (Bandura et al., 1996, 2001; Hymel et al., 2005; Obermann, 2011b) have repeatedly found all items to load onto a single factor. Thus, as Pozzoli, Gini, and Vieno (2012) put it, "previous studies have only investigated the association between a global index of moral disengagement and bullying behavior, thus losing information about the specificity of the different sets of mechanisms of moral disengagement and peer aggression” (p. 380). Because Bandura (1999) originally proposed moral disengagement to be a multidimensional construct, it is important to move beyond prior research in order to examine how specific sub-constructs of moral disengagement contribute to bullying behavior as well as defending behavior with respect to bullying. This kind of research would expand our theoretical and empirical understanding of moral disengagement.

As exceptions, a few studies have demonstrated four-factor solutions of moral disengagement. Osofsky, Bandura, and Zimbardo (2005) identified the factors of moral justification, economic and security justifications, dehumanization, and non-responsibility among prison personnel in relation to executing the death penalty. Pozzoli et al. (2012) confirmed the four major domains of moral disengagement (cognitive restructuring, minimizing one's agentive role, disregarding/distorting the consequences, and victim attribution) as distinct factors. In their study, only cognitive restructuring was significantly related to probullying behavior (defined as initiating bullying, or assisting or reinforcing bullies) at the individual level. Although a few other studies have analyzed how the eight mechanisms of moral disengagement are associated with aggression (e.g., Pornari \& Wood, 2010), no studies so far have confirmed these mechanisms by factor analysis.

Developing the important research agenda initiated by Pozzoli et al. (2012), Thornberg and Jungert (2013b) developed a scale to assess moral disengagement in bullying that origi- 
nally consisted of 55 items, designed to tap the eight mechanisms of moral disengagement. The explorative factor analysis (EFA) of the 55-item scale revealed several cross-loadings. A systematic and iterative process of repeated EFA procedures and item analyses lead to a final seven-factor structure based on 18 of the 55 original items. Dehumanization and blaming the victim were merged into one factor (victim attribution).

\section{The Present Study}

The aim of the present paper was to perform a confirmatory factor analysis of the new moral disengagement in bullying scale (Thornberg \& Jungert, 2013b) and then examine how the seven mechanisms are associated with bullying and defending behavior. In line with the literature, it was hypothesized that moral disengagement as a global index would be positively associated with bullying behavior and negatively associated with defending behavior. It was also hypothesized that boys would express higher levels of moral disengagement than girls. Even though all mechanisms can be potentially associated with bullying as well as defending, Pozzoli et al. (2012) have shown that not all of the major domains are related to pro-bullying. In their study, cognitive reconstruction was the only one that was positively related to pro-bullying at individual level. Based on that, we hypothesized that there would be a significant association between bullying behavior and each of the three mechanisms of cognitive reconstruction: moral justification, euphemistic labeling, and advantageous comparison. In addition, because some studies (Hara, 2002; Thornberg \& Knutsen, 2011) have found a positive association between victim attribution and bullying behavior, we also hypothesized that victim attribution would be positively related to bullying behavior in this current study.

The present study is the first to examine the relationships between mechanisms of moral disengagement and defending behavior in the context of bullying. In the traditional bystander literature, victim attribution and diffusion of responsibility, in particular, have been discussed 
as rationales supporting passive bystander behavior (Bierhoff, 2002; Latané \& Darley, 1970; Piliavin, Piliavin, \& Rodin, 1975). For example, rescuers during the Holocaust displayed a strong sense of agency and dismissed the widespread socio-cultural process of dehumanization of Jews and other persecuted minorities. For them, all people were the same and entitled to the same rights because they were “just like us” (Monroe, 2008). Diffusion of responsibility is one of the identified social psychological processes behind the bystander effect, which refers to a decreased probability of intervening in an emergency when other people (bystanders) are present (Bierhoff, 2002; Darley \& Latené, 1968; Latané \& Darley, 1970; Piliavin et al., 1975). Hence, with reference to bystander literature, we hypothesized that diffusion of responsibility and victim attribution would be negatively associated with defending behavior. Moreover, since previous findings have shown that moral disengagement is not related to the victim role, we simply hypothesized that none of the mechanisms of moral disengagement would be associated with victimization. Finally, because previous studies have consistently revealed that boys disengaged morally more than girls, we hypothesized that boys would endorse more highly all seven mechanisms of moral disengagement.

\section{Method}

\section{Participants}

Three hundred and seventy-two children (193 boys, 178 girls, and 1 missing value) ranging in age from 10 to 14 years (M.12.63 years; SD..81) and attending seven Swedish elementary schools participated in the study on a voluntary basis. This age group was chosen because a Swedish national report has revealed that bullying is more frequent in elementary and lower secondary schools as compared to upper secondary schools (Skolverket, 2010), and retrospective research has shown that bullying is most frequently remembered as occurring between approximately 11-13 years of age (Eslea \& Rees, 2001). Socioeconomic and ethnic 
background data were not gathered on an individual level, although the sample was recruited from schools located in neighborhoods of different socioeconomic status, representing both the lower and middle classes. Based on information from the schools, the majority of the participants have a Swedish ethnic background. Informed consent was given by all children and their parents.

\section{Procedure and Measures}

The participants were given the questionnaires, and filled them out in their ordinary classroom setting. A student teacher, at the end of her teacher training, was present in every classroom during the data gathering, and the definition of bullying on the front page of the questionnaire, based on Olweus' definition (1993), was read aloud to the participants.

Bullying means that a student, or a group of students, repeatedly say or do nasty and unpleasant things to another student. It's also bullying when others repeatedly exclude a student. But it's not bullying when two students of about the same strength quarrel or fight. Jokes between friends are not bullying if everyone involved thinks it’s okay. But it's bullying if a student, or a group of students, repeatedly makes fun of or teases another student in a way he or she doesn’t like.

Moral Disengagement in Bullying. We used an 18-item Moral Disengagement in Bullying Scale (MDBS) to measure the degree in which children morally disengage in bullying situations, validated for school children (Thornberg \& Jungert, 2013b). The items in MDBS represent seven mechanisms of moral disengagement: moral justification, euphemistic labeling, advantageous comparison, displacement of responsibility, diffusion of responsibility, distorting consequences, and victim attribution. Children rated each item on a seven-point scale, where 1 means “disagree” and 7 means "agree” (see the Results Section and Table I for 
an overview of the items, confirmatory factor analysis, and Cronbach's alphas or $r$ due to number of items).

Victimization. A six-item scale was designed to measure participants' victimization. The children were asked, "How often have one or more students done the following things at school toward you in the past 3 months?” Two items measured physical victimization: "Beat or kicked me in order to make me hurt or sad," and "Shoved or held me against my will." Two items measured verbal victimization: “Teased and called me mean names," and "Made fun of or joked about me in a way I didn’t like.” Two items measured relational victimization: "Left me out and not allowed me to be with them," and "Spread mean rumors or lies about me.” The children indicated how often they have been the victims of the behavior described in each item on a five-point scale ( $0=$ "It haven’t happen to me”, $1=$ "A $\mathrm{A}$ couple of times,” 2=“ 2 or 3 times a month,” 3=“About once a week,” 4="Several times a week”) (Cronbach's $\alpha=.85$ ). In the sample, 32\% reported zero across all items, and 21\% reported "2 or 3 times a month" on at least one of the items.

Bullying Behavior. The same six-item scale was designed to measure participants’ own bullying behavior. The children were asked, "How often have you alone or together with others, done the following things at school toward the same person in the past 3 months?” This was followed by the six behavioral items described above. The children indicated how often they have done the behavior described in each item on a five-point scale ( $0=$ ="I haven’t done that,” 1=“A couple of times,” $2=$ =“2 or 3 times a month,” $3=$ "About once a week,” $4=$ =Several times a week") (Cronbach’s $\alpha=73$ ). In the sample, 49\% reported zero across all items, and $10 \%$ reported " 2 or 3 times a month" on at least one of the items.

Defending Behavior. A 21-item scale was designed to measure participants’ defending behavior as bystanders in bullying situations. This scale consisted of three sections. In the first section (physical bullying), the children were asked, "When one or more students are 
beating, kicking, harshly shoving, or holding another student in order to make the person upset, what do you usually do?” In the second section (verbal bullying), the children were asked, "When one or more students are teasing, threatening, or calling another student mean names in order to make the person upset, what do you usually do?” In the third section (relational bullying), the children were asked, "When one or more students are freezing a student out or spreading mean rumors about the student, what do you usually do?” With the exception of the last item in the relational bullying section, seven identical items followed the question in each of the three sections: "I go and tell a teacher," "I try to make them stop," "I try to comfort the student," "I try to defend the student," "I try to get others to help the student," "I tell them to stop bullying," and "I step between and try to make them stop” (in the relational bullying section, the last item was instead, "I tell the student that he/she can be with us”). The children indicated how often they responded in accordance with the behavior described in each item (0=“never,” 1=“seldom,” 2=“sometimes,” 3=“usually,” 4=“always”). Cronbach’s alphas were as follows: defending in physical bullying, $\alpha=83$; verbal bullying, $\alpha=87$; relational bullying, $\alpha=89$; total across the three sections, $\alpha=94$.

\section{Results}

\section{Confirmatory Factor Analyses}

In order to test whether the data fitted a seven factor model of moral disengagement, we performed a confirmatory factor analysis. CFA was carried out using the EQS program (Bentler, 2008). The seven factors were allowed to be correlated but errors were not correlated. In anticipation of the possibility that variables might not be normally distributed, ML and Robust methods were used simultaneously when testing the model. The chi-square test (Yuan \& Bentler, 1998) revealed a good fit to the data, as it was not significant; Satorra-Bentler scaled $\chi^{2}(114, N=372)=118.56, p=.366$. The other goodness-of-fit indices confirmed the chi- 
square test, as they too revealed good model fit: $\chi^{2} / \mathrm{df}=1.04, \mathrm{CFI}=.99, \mathrm{RMSEA}=.01, .90 \mathrm{CI}$ $(.00, .03)$. Table 1 shows the factor loadings for all items (standardized solution). It can be seen that the seven factors are Moral justification (F1), Euphemistic labeling (F2), Advantageous comparison (F3), Displacement of responsibility (F4), Diffusion of responsibility (F5), Distorting consequences (F6), and Victim attribution (F7).

We tested whether the seven-factor solution would be improved by the addition a single higher-order factor on which all seven correlated factors loaded. The chi-square test was significant, Satorra-Bentler scaled $\chi^{2}(135, N=372)=355.46, p<.001$, and the other goodness-of-fit indices also indicated a poor fit to the data: $\chi^{2} / \mathrm{df}=2.63$, CFI $=.67$, RMSEA $=.08, .90 \mathrm{CI}(.06, .08)$. Hence, our data indicated that there was not a single higher-order factor and that the seven-factor solution was the superior model.

- Insert Table 1 about here -

\section{Intercorrelations}

Table 2 presents Pearson correlations between the variables of the study. Age correlated with only two variables. With age, children were somewhat less prone to defend a victim, and somewhat more prone to make victim attributions. The correlation matrix revealed that girls were less likely to bully, and more likely to defend a victim. Bullying was significantly and negatively associated with defending, and positively associated with victimization and with six of the seven variables of moral disengagement. Victimization in turn, was significantly but weakly related to victim attribution and distortion of consequences. In contrast to bullying, defending was significantly and negatively associated with five of the seven variables of moral disengagement. Correlations among the seven moral disengagement mechanisms ranged from .18 to .45 . Finally, the global measure of moral disengagement was significantly 
and positively related to bullying, victimization and to all seven dimensions of moral disengagement, with correlations ranging from .54 to .76.

- Insert Table 2 about here -

\section{Gender Differences}

The correlation matrix in Table 2 revealed that gender was associated with moral disengagement and with five of the seven mechanisms of moral disengagement. Gender differences in the global scale of moral disengagement in bullying and its seven subscales were therefore investigated further. Levine's test indicated that the assumption for equality of variances was violated for the global index of moral disengagement and for five of the seven mechanisms of moral disengagement (moral justification, euphemistic labeling, diffusion of responsibility, distorting consequences, and victim attribution. Therefore MANOVA was not appropriate. Instead we used Welch $F$ for these six comparisons and one-way ANOVA for the other three. Controlling for familywise error rates, $p<.006$ was considered significant. Compared with girls, boys expressed significantly higher levels of global moral disengagement, euphemistic labeling, diffusion of responsibility, distorting consequences, and victim attribution (see Table 3). However, the effect size was more or less small in each comparison (with the exception of euphemistic labeling in which the effect size could be interpreted as "medium" or moderate, see Cohen, 1988).

- Insert Table 3 about here -

\section{Regression of Bullying Behavior}

A two-step hierarchical regression analysis was performed with bullying behavior as the dependent variable. Age, gender, victimization and defending behavior were entered in the first step as control variables. In the second step, the seven mechanisms of moral disengage- 
ment were entered with the SPSS stepwise method. The results are presented in Table 4. The final model explained $31 \%$ of the variance. Among the control variables, gender was significantly and negatively related to bullying, indicating that boys bully significantly more often than girls. Whereas victimization was significantly and positively related to bullying, defending behavior was significantly and negatively associated with bullying. Among the moral disengagement mechanisms, only moral justification and victim attribution were significantly related to bullying.

- Insert Table 4 about here -

\section{Regression of Defending Behavior}

A similar two-step hierarchical regression analysis was performed with defending behavior as the dependent variable and substituting bullying behavior instead of defending behavior as a control variable. The final model explained $13 \%$ of the variance. Girls are more likely to defend victims. In addition, bullying behavior was significantly and negatively associated with defending. Among the moral disengagement mechanisms, diffusion of responsibility and victim attribution were significantly and negatively related to defending.

- Insert Table 5 about here -

\section{Regression of Victimization}

A final two-step hierarchical regression analysis was performed with victimization as the dependent variable and with defending behavior instead of victimization among the control variables. None of the moral disengagement variables entered into the second step. The final model explained $19 \%$ of the variance. Age was significantly related to victimization. Younger children are more likely to be victims. In addition, bullying behavior was positively and significantly associated with victimization. 
- Insert Table 6 about here -

\section{Discussion}

To better understand children's morality in relation to aggression such as bullying, focusing on moral principles or rules is not enough: We already know that children generally judge bullying as wrong using moral reasons such as referring to its harmful consequences when justifying their judgments (cf., Thornberg, 2010a), and that bullies are as able as defenders to judge moral permissibility of harmful actions (Gini et al., 2011). In his theory of moral disengagement, Bandura (1999, 2002, 2004) suggested that there are socio-cognitive processes through which people can disengage from moral standards and instead behave inhumanely toward other people. In accordance with the theory of moral disengagement and previous research, moral disengagement in the current study was positively associated with bullying behavior (cf., Gini et al., 2011; Hymel et al., 2005; Menesini et al., 2003; Obermann, 2011b; Perren \& Gutzwiller-Helfenfinger, 2012; Perrenet al., 2011), and negatively associated with defending behavior (cf., Gini, 2006; Obermann, 2011a; Thornberg \& Jungert, 2013a).

Whereas previous studies have demonstrated or measured moral disengagement as a unidimensional construct, Pozzoli et al. (2012) found a four-factor solution that confirmed the four major domains of moral disengagement (cognitive restructuring, minimizing one’s agentive role, disregarding/distorting the consequences, and victim attribution). In their study, only cognitive restructuring was significantly related to pro-bullying behavior at the individual level. Our findings made a unique contribution to the literature by showing that not all three mechanisms of cognitive restructuring appear to be activated in bullying. By examining moral disengagement at the mechanism level instead of major domain level, the present study revealed that whereas moral justification was positively associated with bullying behavior, 
euphemistic labeling and advantageous comparison were not associated with bullying behavior at all. Because moral justification interprets the aggressive and harmful act as serving a moral purpose, a person who subscribes to this belief, "apart from being more likely to engage in this behavior, is also likely to experience positive feelings for doing so (e.g. pride, self-approval) which, in turn, further facilitates harmful behavior” (Pornari \& Wood, 2010, p. 90). Hence, he or she can consider him or herself a moral agent while inflicting harm on others (Bandura, 2002).

Moreover, the current data revealed a positive relationship between victim attribution and bullying, which has also been found in other studies (Hara, 2002; Thornberg \& Knutsen, 2011). In contrast, Pozzoli et al. (2012) did not find victim attribution associated with probullying at individual level. One possible explanation of the different findings might be that Pozzoli et al. (2012) examined moral disengagement in antisocial behavior (i.e., a broader category of behavior than bullying) and its association with pro-bullying behavior (also a broader category compared to bullying behavior). In addition, whereas bullying behavior was measured by self-report in the present study, Pozzoli et al. (2012) measured pro-bullying behavior by peer nominations.

Furthermore, Pozzoli et al. (2012) performed multilevel modeling in which they found that victim attribution predicted pro-bullying behavior at school class level. In line with this, qualitative studies have shown how children collectively dehumanize and blame the victim in an effort to explain and justify their bullying toward the victim (Lahelma, 2004; Teräsahjo \& Salmivalli, 2003; Thornberg, in press). Further research on peer culture, as well as the interplay between group/class and individual levels of analysis, will lead to a better understanding of the relationship between bullying and victim attribution. With reference to the attribution theory, Gini (2008) argues that "in the case of potentially harmful events, blaming other 
individuals is a very real self-serving attribution and, in particular, blaming the victims for their fate allows people to distance themselves from thoughts of suffering” (p. 337).

Besides being positively linked to bullying, victim attribution was negatively associated with defending behavior in the present study. Thus, if children are less prone to attribute the cause of bullying to the victim, they seem to be more likely to help the victim. The low frequency of defending behavior among bystanders in school bullying found in previous studies (Craig \& Pepler, 1998; Craig, Pepler \& Atlas, 2000; Hawkins, Pepler \& Craig, 2001; O’Connell, Pepler \& Craig, 1999) might therefore be linked to the widespread tendency among children and adolescents to think that victims have, at least partially, caused the bullying (e.g., Frisén, Holmqvist, \& Oscarsson, 2008; Teräsahjo \& Salmivalli, 2003; Thornberg, 2010b, in press; Thornberg \& Knutsen, 2011; Varjas et al., 2008). Dehumanizing and blaming the victim helps the passive bystander to reduce or neutralize empathic distress and to avoid feelings of guilt for inaction (cf., Hoffman, 2000). Furthermore, the negative relationship between diffusion of responsibility and defending behavior in the present study indicates that children who are more prone to dilute responsibility among the peer group are also less likely to help victims, which confirms the link between diffusion of responsibility and passive bystander behavior found in previous research (e.g., Darley \& Laténe, 1968; Latené \& Darley, 1970; Piliavin, Piliavin \& Rodin, 1975).

Even though victimization was significantly, although weakly, associated with victim attribution and distorting consequences in correlation analyses, there was also a moderate and significant association between victimization and bullying. When bullying behavior was controlled in the regression analysis, none of the moral disengagement mechanisms were found to be associated with victimization.

Furthermore, the current study showed that boys employ significantly higher levels of euphemistic labeling, diffusion of responsibility, distorting consequences, and victim 
attribution than girls, which sheds new light on previous findings indicating that boys tend to display a higher overall level of moral disengagement (Almeida et al., 2010; Bandura et al., 1996, 2001; Barchia\&Bussey, 2010; Obermann, 2011b; Perren \& Gutzwiller-Helfenfinger, 2012; Thornberg \& Jungert, 2013a). Further research is needed to examine how the gender differences in these moral disengagement mechanisms might contribute to other gender differences such as girls being more prone to show positive attitudes toward victims (e.g., Menesini et al., 1997; Rigby, 1996; Rigby \& Slee, 1993), more likely to defend victims, and less likely to bully or reinforce bullies than boys (Gini et al., 2008; O’Connell et al., 1996; Pozzoli et al., 2012; Salmivalli et al., 1996; Salmivalli \& Voeten, 2004; Scheithauer, Hayer, Petermann \& Jugert, 2006).

Summing up, the current findings highlight the importance of differentiating and measuring the mechanisms of moral disengagement empirically found by Thornberg and Jungert (2013b) and confirmed here. Four of the seven mechanisms showed gender differences, yet only a few of the mechanisms contributed to explaining bullying and defending behavior. Bullying behavior is linked to the selective activation of moral justification and victim attribution, while refraining from defending the victim is linked to the selective activation of victim attribution and diffusion of responsibility. According to Bandura’s (1999, 2002) theory, moral disengagement mechanisms operate together to promote inhumanity in the transactions of everyday life. We therefore need not only to examine moral disengagement as a general construct - which we still see as relevant given the intercorrelations between its mechanisms - but also to investigate the selective activation and conjoint operation of its mechanisms across different forms of aggression, social roles in aggressive situations, contexts, and subgroups.

\section{Limitations and Implications}


Some limitations of this study should be noted. First, our findings are based on self-report data. In addition to social desirability effects, some associations that we found might also be inflated as a function of shared method variance (Cornell \& Bandyopadhyay, 2010). Second, we used a cross-sectional design, and we are therefore not able to pin-point the direction of effects between moral disengagement and bullying-related behaviors. Third, the defending behavior scale assumes that the participants have witnessed physical, verbal and relational aggression among their peers. Nevertheless, it is possible that the response option "never" could have been misinterpreted among participants as never having witnessed aggression rather than never having intervened in the way described. However, they were in fact asked to rate what they usually did when one or more students acted in accordance with at least one of the described aggressive behaviors. Fourth, some of the alphas and $r$ were low among the subscales in the MDBS, which weakens the reliability of these subscales. However, the small numbers of items probably contributed to lowering alpha and $r$ values.

Despite these limitations, the findings of our study show that some, but not all moral disengagement mechanisms are related to gender, age, bullying, and defending. The study offers greater precision on how to apply moral disengagement theory in counteracting bullying in school. Prevention and intervention programmes should address victim attributions and responsibility diffusion in order to reduce bullying and enhance defending among children. Moreover, moral justification should be addressed in school in order to reduce bullying behavior. Overall, we agree with Pozzoli et al. (2012) that it would be interesting to conduct randomized control trials to experimentally verify whether decreasing these distortions of morality would contribute to weakening the association between moral disengagement and bullying behavior. Furthermore, it would allow us to test to what degree changes in different moral disengagement mechanisms predict changes in bullying as well as defending, and hence to further test the findings of the current study. 


\section{References}

Almedia, A., Correia, I., \& Marinho, S. (2010). Moral disengagement, normative beliefs or peer group, and attitudes regarding roles in bullying. Journal of School Violence, 9, 2336. doi: 10.1080/15388220903185639.

Bandura, A. (1997). Self-efficacy: The exercise of control. New York, NY: W. H. Freeman and Company.

Bandura, A. (1999). Moral disengagement in the perpetration of inhumanities. Personality and Social Psychology Review, 3, 193-209. doi: 10.1207/s15327957pspr0303_3.

Bandura, A. (2002). Selective moral disengagement in the exercise of moral agency. Journal of Moral Education, 31, 101-119. doi: 10.1080/0305724022014322.

Bandura, A. (2004). Selective exercise of moral agency. In T. A. Thorkildsen \& H. J. Walberg (Eds.), Nurturing morality (pp. 37-57). Boston: Kluwer Academic.

Bandura, A., Barbaranelli, C., Caprara, G. V., \& Pastorelli, C. (1996). Mechanisms of moral disengagement in the exercise of moral agency. Journal of Personality and Social Psychology, 71, 364-374. doi: 10.1037/0022-3514.71.2.364.

Bandura, A., Caprara, G. V., Barbaranelli, C., \& Pastorelli, C. (2001). Sociocognitive selfregulatory mechanisms governing transgressive behavior. Journal of Personality and Social Psychology, 80, 125-135. doi: 10.1037/0022-3514.80.1.125.

Barchia, K., \& Bussey, K. (2010). Individual and collective social cognitive influences on peer aggression: Exploring the contribution of aggression efficacy, moral disengagement, and collective efficacy. Aggressive Behavior, 35, 1-14. doi: 10.1002/ab.20375.

Barriga, A. Q., Sullivan-Cosetti, M., \& Gibbs, J. C. (2009). Moral cognitive correlates of empathy in juvenile delinquents. Criminal Behaviour and Mental Health, 19, 253-264. doi: 10.1002/cbm.740. 
Bentler, P.M. (1999). EQS Structural Equations Program Manual. Encino, CA: Multivariate Software.

Bierhoff, H-W. (2002). Prosocial behavior. Hove: Psychology Press.

Cohen, J. (1988). Statistical power analysis for the behavioral sciences (2nd ed.). Hillsdale, NJ: Lawrence Earlbaum.

Cornell, D. G., \&Bandyopadhyay, S. (2010). The assessment of bullying. In S. R. Jimerson, S. M. Swearer \& D. L. Espelage (Eds.), Handbook of bullying in schools: An international perspective (pp. 265-276). New York, NY: Routledge.

Craig, W. \& Pepler, D. (1998). Observations of bullying and victimization in the school yard. Canadian Journal of Social Psychology, 13, 41-60. doi: 10.1177/082957359801300205.

Craig, W. M., Pepler, D. \& Atlas, R. (2000). Observations of bullying in the playground and in the classroom. School Psychology International,21, 22-36. doi: $10.1177 / 0143034300211002$

Darley, J. M., \& Latené, B. (1968). Bystander intervention in emergencies: Diffusion of responsibility. Journal of Personality and Social Psychology, 8, 377-383. doi: 10.1037/h0025589.

Eslea, M., Menesini, E., Morita, Y., O’Moore, M., Mora-Merchán, J. A., Pereira, B., et al. (2003). Friendship and loneliness among bullies and victims: Data from seven countries. Aggressive Behavior, 30, 7-83. doi: 10.1002/ab.20006.

Frisén, A., Holmqvist, K. \& Oscarsson, D. (2008). 13-year-olds’ perception of bullying: Definitions, reasons for victimisation and experience of adults' response. Educational Studies, 34, 105-117. doi: 10.1080/03055690701811149.

Gini, G. (2006). Social cognition and moral cognition in bullying: What's wrong? Aggressive Behavior, 32, 528-539. doi: 10.1002/ab.20153. 
Gini, G. (2008). Italian elementary and middle school students’ blaming the victim of bullying and perception of school moral atmosphere. The Elementary School Journal, 108, 335-354. doi: 10.1086/528975.

Gini, G., Pozzoli, T., \& Hauser, M. (2011). Bullies have enhanced moral competence to judge relative to victims, but lack moral compassion. Personality and Individual Differences, 50, 603-608. doi:10.1016/j.paid.2010.12.002.

Gini, G., Pozzoli, T., Borghi, F., \& Franzoni, L. (2008). The role of bystanders in students' perception of bullying and sense of safety. Journal of School Psychology, 46, 617-638. doi: 10.1016/j.jsp.2008.02.001.

Hair, J. F., Anderson, R. E., Tatham, R.L., et al. (1995). Multivariate Data Analysis. (4th ed.) New York: Macmillan Publishing Company.

Hara, H. (2002). Justifications for bullying among Japanese schoolchildren. Asian Journal of Social Psychology, 5, 197-204. doi: 10.1111/1467-839X.00104.

Hawkins, D. L., Pepler, D. J., \& Craig, W. M. (2001). Naturalistic observations of peer interventions in bullying. Social Development, 10, 512-527. doi: 10.1111/14679507.00178.

Hoffman, M. L. (2000). Empathy and moral development. Cambridge: Cambridge University Press.

Hu, L., \& Bentler, P. M. (1999). Cutoff criteria for fit indexes in covariance structure analysis: conventional criteria versus new alternatives. Structural Equation Modeling: A Multidisciplinary Journal, 6, 1-55. doi: 10.1080/10705519909540118.

Hymel, S., Rocke-Henderson, N., \& Bonanno, R. A. (2005). Moral disengagement: A framework for understanding bullying among adolescents. Journal of Social Sciences, Special Issue, 8, 1-11. 
Hymel, S., Schonert-Reichl, K. A., Bonanno, R. A., Vaillancourt, T., \& Rocke Henderson, N. (2010). Bullying and morality. In S. R. Jimerson, S. M. Swearer, \& D. L. Espelage (Eds.), Handbook of bullying in schools: An international perspective (pp. 101-118). New York, NY: Routledge.

Lahelma E. (2004). Tolerance and understanding? Students and teachers reflect on differences at school. Educational Research and Evaluation, 10, 3-19. doi: 10.1076/edre.10.1.3.26297.

Latané, B. \& Darley, J. M. (1970). The unresponsive bystander: Why doesn’t he help? New York: Meredith Corporation.

Menesini, E., Sanchez, V., Fonzi, A., Ortega, R., Costabile, A., \& Feudo, G. L. (2003). Moral emotions and bullying: A cross-national comparison of differences between bullies, victims and outsiders. Aggressive Behavior, 29, 515-530. doi: 10.1002/ab.10060.

Monroe, K. R. (2008). Cracking the code of genocide: The moral psychology of rescuers, bystanders, and Nazis during the Holocaust. Political Psychology, 29, 699-736. doi: 10.1111/j.1467-9221.2008.00661.x.

Nucci, L. P. (2001). Education in the moral domain. Cambridge: Cambridge University Press.

Obermann, M-L. (2011a). Moral disengagement among bystanders to school bullying. Journal of School Violence, 10, 239-257. doi: 10.1080/15388220.2011.578276.

Obermann, M-L. (2011b). Moral disengagement in self-reported and peer-nominated school bullying. Aggressive Behavior, 37, 133-144. doi: 10.1002/ab.20378.

Osofsky, M. J., Bandura, A., \& Zimbardo, P. G. (2005). The role of moral disengagement in the execution process. Law and Human Behavior, 29, 371-393. doi: 10.1007/s10979005-4930-1.

Olweus, D. (1993). Bullying at school. Cambridge, MA: Blackwell. 
O’Connell, P., Pepler, D. \& Craig, W. (1999). Peer involvement in bullying: Insight and challenges for observation. Journal of Adolescence, 22, 437-452. doi: 10.1006/jado.1999.0238.

Paciello, M., Fida, R., Tramontano, C., Lupinetti, C., \& Caprara, G. V. (2008). Stability and change in moral disengagement and its impact on aggression and violence in late adolescence. Child Development, 79, 1288-1309. doi: 10.1111/j.14678624.2008.01189.x.

Pelton, J., Gound, M., Forehand, R. \& Brody, G. (2004). The moral disengagement scale: Extension with an American minority sample. Journal of Psychopathology and Behavioral Assessment, 26, 31-39. doi: 10.1023/B:JOBA.0000007454.34707.a5.

Perren, S., \& Gutzwiller-Helfenfinger, E. (2012). Cyberbullying and traditional bullying in adolescence: Differential roles of moral disengagement, moral emotions, and moral values. European Journal of Developmental Psychology, 9, 195-209. doi: 10.1080/17405629.2011.643168.

Piliavin, I. M., Piliavin, J. A., \& Rodin, J. (1975). Costs, diffusion, and the stigmatized victim. Journal of Personality and Social Psychology, 32, 429-438. doi: 10.1037/h0077092.

Pornari, C. D., \& Wood, J. (2010). Peer and cyber aggression in secondary school students: The role of moral disengagement, hostile attribution bias, and outcome expectancies. Aggressive Behavior, 36, 81-94. doi: 10.1002/ab.20336.

Pozzoli, T., Gini, G. \& Vieno, A. (2012). Individual and class moral disengagement in bullying among elementary school children. Aggressive Behavior, 38, 378-388. doi: 10.1002/ab.21442. 
Rigby, K. (1996). Bullying in schools and what we can do about it. London: Jessica Kingsley.

Rigby, K., \& Slee, P. T. (1993). Dimensions of interpersonal relation among Australian children and implications for psychological well-being. Journal of Social Psychology, 133, 33-42. doi: 10.1080/00224545.1993.9712116.

Salmivalli, C., Lagerspetz, K., Björkqvist, K., Östermalm, K., \& Kaukiainen, A. (1996). Bullying as a group process: Participant roles and their relations to social status within the group. Aggressive Behavior, 22, 1-15. doi: 10.1002/(SICI)10982337(1996)22:1<1::AID-AB1>3.0.CO;2-T

Salmivalli, C. \& Voeten, M. (2004). Connections between attitudes, group norms, and behaviour in bullying situations. International Journal of Behavioral Development, 28, 246-258. doi: 10.1080/01650250344000488.

Scheithauer, H., Hayer, T., Petermann, F., \& Jugert, G. (2006). Physical, verbal, and relational forms of bullying among German students: Age trends, gender differences, and correlates. Aggressive Behavior, 32, 261-275. doi: 10.1002/ab.20128.

Skolverket (2010). Attityder till skolan 2009: Elevernas och lärarnas attityder till skolan (Report 344). Stockholm: Fritzes.

Teräsahjo, T., \& Salmivalli, C. (2003). “She is not actually bullied”': The discourse of harassment in student groups. Aggressive Behavior, 29, 134-154. doi: 10.1002/ab.10045.

Thornberg, R. (2010a). A study of children's conceptions of school rules by investigating their judgments of transgressions in the absence of rules. Educational Psychology, 30, 583-603.

Thornberg, R. (2010b). Schoolchildren’s social representations on bullying causes. Psychology in the Schools, 47, 311-327. doi: 10.1080/01443410.2010.492348. 
Thornberg, R. (in press). School bullying as a collective action: Stigma processes and identity struggling. Children and Society. doi: 10.1111/chso.12058.

Thornberg, R., \& Jungert, T. (2013a). Bystander behavior in bullying situations: Basic moral sensitivity, moral disengagement and defender self-efficacy. Journal of Adolescence, 36, 475-483. doi: 10.1016/j.adolescence.2013.02.003

Thornberg, R., \& Jungert, T. (2013b). Moral disengagement in bullying. Paper presented at the 41th Congress of Nordic Educational Research Association at the University of Iceland, Reykjavik, Iceland, 7-9 March, 2013.

Thornberg, R., \& Knutsen, S. (2011). Teenagers’ explanations of bullying. Child and Youth Care Forum, 40, 177-192. doi: 10.1007/s10566-010-9129-z.

Turiel, E. (1983). The development of social knowledge. Cambridge: Cambridge University Press.

Varjas, K., Meyers, J., Bellmoff, L., Lopp, E., Birckbichler, L., \& Marshall, M. (2008). Missing voices: Fourth through eight grade urban students’ perceptions of bullying. Journal of School Violence, 7, 97-118. doi: 10.1080/15388220801973912. 


\section{Table 1}

Confirmatory Factor Analysis of the Moral Disengagement in Bullying Scale.

\begin{tabular}{llllllll}
\hline Items & F1 & F2 & F3 & F4 & F5
\end{tabular}

1. It's okay to harm another person a couple of times a week if

.685

F6 F7 General

you do that to protect your friends

12. It's okay to hurt a person a couple of times a week if you do

8. There's nothing wrong with name-calling a person a bit every

day as long as you just do it as a joke

10. Saying mean things to a certain person a couple of times a

week doesn't matter. It's just about joking a little with the person

5. Teasing a person a couple of times a week is no big deal

because it's much worse to give the person a beating every week

18.Teasing a person now and then every week is not so bad if you

compare it to hitting and kicking a person every day

7. If students are having a hard time at home, they can't be

blamed for bullying others

13. If students have parents who do bad things toward them, it's

not the students' fault if they then bully other students

16. If a child has got a poor upbringing, it's not the child's fault if

he/she is teasing and beating a person every week

9. If my friends begin to bully a classmate, I can't be blamed for being with them and bullying that person too

15. A student can't help that he/she is bullying another student if all his/her friends are doing it

2. Teasing a person a couple times a week is no big deal because

11. Nobody is harmed by being bullied a bit sometimes

14. It surely won't hurt you to be teased a bit now and then

3. If people are weird, it is their own fault if they get bullied

4. It's okay to bully those who are not like others

Note. F1 = Moral justification ( $r=.59)$; F2 = Euphemistic labeling (Cronbach's $\alpha=.65)$; F3 = Advantageous comparison ( $r=.49$ ); F4 = Displacement of responsibility (Cronbach's $\alpha=.70)$; F5 = Diffusion of responsibility $(r=.26)$; F6 = Distorting consequences $(r=.56)$; F7 = Victim attribution (Cronbach's $\alpha=.64)$; General = Moral Disengagement (Cronbach's $\alpha=.84$ ) 
Table 2

Inter-Correlations between All Variables

\begin{tabular}{|c|c|c|c|c|c|c|c|c|c|c|c|c|c|}
\hline & 1 & 2 & 3 & 4 & 5 & 6 & 7 & 8 & 9 & 10 & 11 & 12 & 13 \\
\hline 1. Age & 1 & & & & & & & & & & & & \\
\hline 2. Gender & -.09 & 1 & & & & & & & & & & & \\
\hline 3. Bullying & .07 & $.19 * * *$ & 1 & & & & & & & & & & \\
\hline 4. Victimization & -.10 & .02 & $.41 * * *$ & 1 & & & & & & & & & \\
\hline 5. Defending & $-.13^{*}$ & $-.20 * * *$ & $-.24 * * *$ & -.06 & 1 & & & & & & & & \\
\hline $\begin{array}{l}\text { 6. Moral } \\
\text { justification }\end{array}$ & .07 & $.12 *$ & $.25 * * *$ & .09 & $-.12 *$ & 1 & & & & & & & \\
\hline $\begin{array}{l}\text { 7. Euphemistic } \\
\text { labeling }\end{array}$ & .01 & $.24 * * *$ & $.20 * * *$ & .02 & $-.20 * * *$ & $.33 * * *$ & 1 & & & & & & \\
\hline $\begin{array}{l}\text { 8. Advantageous } \\
\text { comparison }\end{array}$ & -.08 & .09 & .10 & .08 & -.07 & $.24 * * *$ & $.37 * * *$ & 1 & & & & & \\
\hline $\begin{array}{l}\text { 9. Displacement } \\
\text { of responsibility }\end{array}$ & .01 & .06 & $.11^{*}$ & -04 & -.04 & $.24 * * *$ & $.30 * * *$ & $.32 * * *$ & 1 & & & & \\
\hline $\begin{array}{l}\text { 10. Diffusion of } \\
\text { responsibility }\end{array}$ & -.03 & $.15^{* *}$ & $.21 * * *$ & .03 & $-.23 * * *$ & $.34 * * *$ & $.30 * * *$ & $.27 * * *$ & $.31 * * *$ & 1 & & & \\
\hline $\begin{array}{l}\text { 11. Distorting } \\
\text { consequences }\end{array}$ & .08 & $.21 * * *$ & $.28 * * *$ & $.14^{* *}$ & $-.23 * * *$ & $.33 * * *$ & $.45^{* * *}$ & $.44 * * *$ & $.31 * * *$ & $.37 * * *$ & 1 & & \\
\hline $\begin{array}{l}\text { 12. Victim } \\
\text { attribution }\end{array}$ & $.15^{* *}$ & $.17^{* *}$ & $.38 * * *$ & $.18^{* * *}$ & $-.27 * * *$ & $.29 * * *$ & $.25 * * *$ & $.24 * * *$ & $.18^{* * *}$ & $.36 * * *$ & $.43 * * *$ & 1 & \\
\hline $\begin{array}{l}\text { 13. Moral } \\
\text { disengagement }\end{array}$ & .04 & $.22 * * *$ & $.32 * * *$ & $.12 *$ & $-.23 * * *$ & $.57 * * *$ & $.67 * * *$ & $.64 * * *$ & $.68^{* * *}$ & $.59 * * *$ & $.76 * * *$ & $.54 * * *$ & 1 \\
\hline
\end{tabular}

Note. Gender (girls $=0$, boys $=1$ ); ${ }^{*}=p<.05 ; * *=p<.01$; ${ }^{* * *}=p<.001$; moral disengagement in the table refers to the total score for all MD mechanisms. 
Table 3

Gender Differences in Moral Disengagement Mechanisms

\begin{tabular}{lllllll}
\hline Moral disengagement & Total: $m(s d)$ & Boys: $m$ & Girls: & $F$ & $p$ & Cohen’s $d$ \\
variables & & $(s d)$ & $m(s d)$ & & & \\
& & & & & & \\
\hline Moral justification & $1.76(1.07)$ & $1.89(1.23)$ & $1.63(.85)$ & $5.43^{\mathrm{a}}$ & $n s$ & .24 \\
Euphemistic labeling & $2.40(1.34)$ & $2.71(1.45)$ & $2.06(1.11)$ & $23.28^{\mathrm{a}}$ & .000 & .50 \\
Advantageous comparison & $1.97(1.25)$ & $2.08(1.33)$ & $1.86(1.15)$ & $2.91^{\mathrm{b}}$ & $n s$ & .18 \\
Displacement of responsibility & $2.60(1.38)$ & $2.67(1.42)$ & $2.50(1.33)$ & $1.45^{\mathrm{b}}$ & $n s$ & .13 \\
Diffusion of responsibility & $1.47(.80)$ & $1.58(.90)$ & $1.34(.66)$ & $8.82^{\mathrm{a}}$ & .003 & .31 \\
Distorting consequences & $1.57(.85)$ & $1.74(1.00)$ & $1.38(.58)$ & $18.00^{\mathrm{a}}$ & .000 & .44 \\
Victim attribution & $1.26(.61)$ & $1.36(.78)$ & $1.15(.32)$ & $11.41^{\mathrm{a}}$ & .001 & .35 \\
Moral disengagement & $1.84(.66)$ & $1.97(0.73)$ & $1.68(0.54)$ & $19.57^{\mathrm{a}}$ & .000 & .46
\end{tabular}

Note: $\mathrm{a}=$ Welch $F$; $\mathrm{b}=$ one-way ANOVA; for significance at $.05, p$ has to be lower than

.00625; Moral disengagement in the table refers to the total score for all mechanisms 
Table 4

Regression Analysis of Bullying

B $\quad$ SE B $\quad ß \quad R^{2}$

Model 1

.24

Age

.03

.02

.07

Gender

$-.10$

.03

$-.14 * *$

Victimization

.21

.02

$.40^{* * *}$

Defending

$-.08$

.02

$-.18 * * *$

Model 2

$\begin{array}{llll}\text { Age } & .01 & .02 & .03 \\ \text { Gender } & -.07 & -.03 & -.11^{*} \\ \text { Victimization } & .18 & .02 & .35^{* * *} \\ \text { Defending } & -.06 & .02 & -.12^{* *} \\ \text { Victim attribution } & .13 & .03 & .23^{* * *} \\ \text { Moral justification } & .04 & .02 & .12^{* *}\end{array}$

Note: $F(4,366)=28.82, p<.001$ for the first model; $F(6,364)=27.54, p<.001$ for the second

model; $* * * p<.001 ;{ }^{* *} p<.01 ; * p<.05$ 
Table 5

Regression Analysis of Defending

B $\quad$ SE B $\quad$ B $R^{2}$

Model 1

.09

Age

$-.09$

.05

$-.10 *$

Gender

.23

.08

$.15^{* *}$

Victimization

.02

.06

.02

Bullying

$-.46$

.12

$-.21 * * *$

Model 2

$\begin{array}{llll}\text { Age } & -.09 & .05 & .09 \\ \text { Gender } & .19 & .08 & .12^{*} \\ \text { Victimization } & .02 & .06 & .02 \\ \text { Bullying } & -.29 & .13 & -.14^{*} \\ \text { Diffusion of responsibility } & -.13 & .05 & -.14^{* *} \\ \text { Victim attribution } & -.17 & .07 & -.14^{*}\end{array}$

Note: $F(4,366)=28.82, p<.001$ for the first model; $F(6,364)=27.54, p<.001$ for the second

model; *** $p<.001 ; * * p<.01 ; * p<.05$ 
Table 6

Regression Analysis of Victimization

B $\quad$ SE B $\quad$ B $R^{2}$

Model 1

.19

$\begin{array}{llll}\text { Age } & -.10 & .04 & -.12^{*} \\ \text { Gender } & .06 & .07 & .05 \\ \text { Bullying } & .84 & .10 & .43^{* * * *} \\ \text { Defending } & .02 & .05 & .02\end{array}$

Note: $F(4,366)=20.79, p<.001$ for the first model; because of non-significance, no moral disengagement variables were entered into the second step; ${ }^{* * *} p<.001{ }^{* *} p<.01$; ${ }^{*} p<$ .05 